\title{
Amaranth Microgreens as a Potential Ingredient for Healthy Salads: Sensory Liking and Purchase Intent
}

\author{
Domínguez-Domínguez, Aimeé; ${ }^{1}$ Herrera-Corredor, José Andrés ${ }^{2}$; Argumedo-Macias, Adrián ${ }^{3}$; \\ Ramírez-Rivera, Emmanuel de Jesús ${ }^{4}$; López-Aranda, Erika ${ }^{1}$; Romero-Cruz, Anabel ${ }^{1}$; López-Espíndola Mirna ${ }^{2 *}$ \\ ${ }^{1}$ Instituto Tecnológico Superior de Acatlán de Osorio. Ingeniería en Industrias Alimentarias. Acatlán \\ de Osorio, Puebla, México. ${ }^{2}$ Colegio de Postgraduados Campus Córdoba. Manuel León, Amatlán \\ de los Reyes, Veracruz, México. ${ }^{3}$ Colegio de Postgraduados, Campus Puebla. Cholula, Puebla, \\ México. ${ }^{4}$ Tecnológico Nacional de México /ITS de Zongolica, Zongolica, Veracruz, México \\ *Corresponding author: Imirna@colpos.mx
}

\begin{abstract}
Objective: To identify liking, acceptability, and purchase intent of salads prepared from amaranth microgreens in a mixture with lettuce and carrots.

Design/Methodology/Approach: Seven formulations of amaranth microgreens, lettuce, and carrots were evaluated. The study was conducted through a centralized location consumer study. The level of liking was measured with a 9-point hedonic scale. Acceptability and purchase intent were measured with a binomial scale.

Results: In general, consumers indicated they liked salad samples within a range of 6 (liked slightly) and 7 (liked moderately). Formulation 7 (with the highest proportion of carrot) was liked by consumers in aftertaste, flavor, and overall liking Formulation 3 (a balanced mixture of its three ingredients) was liked in its attributes: colors, texture, appearance, and smell. Overall liking had a significant impact on purchase intent.

Study Limitations/Implications: Study results represent only the segment of the surveyed population, most of which were young people between 18 and 25 years old (60\%).

Findings/Conclusions: Amaranth aroma can impact the liking of amaranth microgreen-based salads without causing rejection. The use of carrots in combination with amaranth microgreens can improve the acceptability of salads. Salad formulations with amaranth proportions of 22 to $33.3 \%$ have more opportunity in their purchase intent.
\end{abstract}

Keywords: amaranth, microgreens, consumers, acceptability, purchase.

\section{INTRODUCTION}

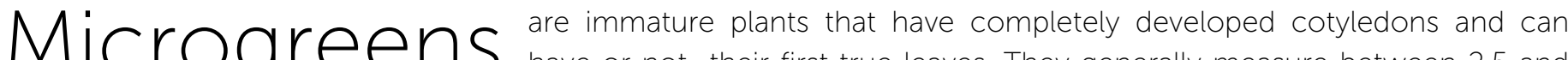

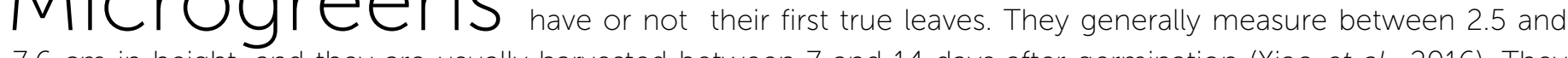
$7.6 \mathrm{~cm}$ in height, and they are usually harvested between 7 and 14 days after germination (Xiao et al., 2016). They represent an alternative for food consumption with functional properties (Xiao et al., 2015). In addition, a small portion of microgreens can provide around $89 \%$ of the daily required intake of vitamins (Kou et al., 2013). Amaranth cultivation in Mexico is primarily directed toward grain production for different processed products, and although the crop is

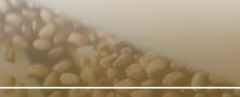

Agroproductividad: Vol. 14, Núm. 4, abril. 2021. pp: 47-51.

Recibido: agosto, 2020. Aceptado: marzo, 2021. 
consumed as a plant in rural areas, it is not common to find these products in supermarkets with similar packaging to other leafy vegetables such as lettuce. The cultivation of amaranth for the production of microgreens could be a diversifying option for the crop, to be used in nutrient-rich foods with functional properties. In order to accomplish this goal, it is necessary to identify the reactions of consumers regarding the use of microgreens, to successfully introduce them into the market. A consumer study will allow the determination of key sensory attributes that impact the level of liking, acceptability, and purchase intent in salads formulated with amaranth microgreens.

Various studies have demonstrated that there is a direct correlation between vegetable consumption and a reduction in the development of chronic illnesses, such as cardiovascular diseases and cancer (Slavin and Lloyd, 2012). It has been found that microgreens generally contain more phytonutrients (such as ascorbic acid, $\alpha$-tocopherol, and $\beta$-carotene) than mature plants, and are excellent sources of vitamins and carotenoids (Chloe et al., 2008). On the sensory side, microgreens can provide intense flavors, vivid colors, and specific textures, while also being able to function as a decorative element in salads or as a new ingredient. In general, the quality of fresh products is related to various sensory attributes such as appearance, texture, and flavor (Xiao et al., 2015). Among all the quality attributes, appearance is the initial attribute that attracts consumers and affects their choice to buy for the first time. However, other characteristics play a crucial role in consumer satisfaction and repeating purchases. To date, there is no information from studies published in the literature about the integration of amaranth microgreens in salads evaluated by consumers.

The use of amaranth microgreens in salads could represent a strategy for diversifying the application of the amaranth crop. Nonetheless, a lack of awareness of this use in consumers can be a limitation. The objective of this study was to identify the liking level, acceptability, and purchase intent of salads prepared using amaranth microgreens mixed with lettuce and carrots.

\section{MATERIALS AND METHODOLOGY}

The study was conducted in the Sensory Testing Laboratory of Colegio de Postgraduados, Córdoba Campus, located on km 348 of the Córdoba-Veracruz Federal Highway, in Amatlán de los Reyes, Veracruz, Mexico.

\section{Plant Material}

For the production of amaranth microgreens, seeds of the Areli variety were used, which were planted in the municipality of Xayacatlán de Bravo, Puebla. The soil used consisted of $60 \%$ loam, $25 \%$ sand, and $15 \%$ compost. The seeds were sprinkled evenly, covered lightly with soil, and fully moistened. They were watered twice a day morning and afternoon. After 5 days, the seeds began to germinate. By the seventh day after planting, the watering schedule was modified: in the morning, around midday, and in the afternoon. This procedure was maintained for 11 days, which was the time it took for the plants to reach the height and characteristics required for cutting. The microgreens were harvested using previously disinfected scissors by cutting the stem approximately one centimeter above the soil. The plants were placed in a plastic container and stored in refrigeration at $4{ }^{\circ} \mathrm{C}$ to avoid oxidation or darkening

The carrots and romaine lettuce were purchased the local market one day before conducting the consumer study.

\section{Mixture Design}

The design of the salad mixtures was based on a simplex triangle where the total proportions of each ingredient (amaranth microgreens, lettuce, and carrots) in the salad were adjusted to sum 100\% according to Table 1. As constraints, a maximum of $80 \%$ and a minimum of $10 \%$ were set for all the ingredients.

\section{Salad Preparation}

Before preparing the salads, the ingredients were selected to verify the absence of physical damage, contamination, or undesirable materials. All the ingredients were washed and disinfected in a $1 \%$ sodium hypochlorite solution for 3 to $5 \mathrm{~min}$. The lettuce and carrots were cut into long segments of approximately $5 \mathrm{~cm} \times 1 \mathrm{~cm}$, adequate for the salad presentation. The

\begin{tabular}{|c|c|c|c|c|}
\hline Formulation & $\begin{array}{c}\text { Lettuce } \\
\%\end{array}$ & $\begin{array}{c}\text { Amaranth } \\
\%\end{array}$ & $\begin{array}{c}\text { Carrot } \\
\%\end{array}$ & $\begin{array}{c}\text { Total } \\
\%\end{array}$ \\
\hline F1 & 80.0 & 10.0 & 10.0 & 100 \\
\hline F2 & 56.0 & 22.0 & 22.0 & 100 \\
\hline F3 & 33.3 & 33.3 & 33.3 & 100 \\
\hline F4 & 22.0 & 56.0 & 22.0 & 100 \\
\hline F5 & 22.0 & 22.0 & 56.0 & 100 \\
\hline F6 & 10.0 & 80.0 & 10.0 & 100 \\
\hline F7 & 10.0 & 10.0 & 80.0 & 100 \\
\hline
\end{tabular}


amaranth microgreens were only trimmed of excess stem. Given that salads are usually eaten with dressing, a neutral dressing of lime and honey (1:1) was used in all the formulations. The dressing selection sought one that was simple, easy to prepare, and appropriate for the mix of ingredients while having the lowest impact on salad taste.

All the ingredients in the formulations presented to the consumers were weighed individually to guarantee proportions according to the mixture design. Weighing was done using a Scout ${ }^{\circledR}$ Pro (Ohaus Corporation, 194 Chapin Road NJ07058, USA) analytical scale. The ingredients were manually placed and mixed on disposable plates. The total weight of the amaranth microgreens, lettuce and carrots that was presented to the consumer was $30 \mathrm{~g}$, and as a final step, $5 \mathrm{ml}$ of dressing was added.

\section{Consumer Study}

The study was conducted with consumers in a central location modality. The evaluation was carried out at Córdoba Campus of Colegio de Postgraduados. To collect the answers, a questionnaire was used with three sections: 1) consumer demographic data; 2) evaluation of salad liking for 7 sensory attributes (appearance, color, aroma, mouth feel or texture, flavor, aftertaste, and general liking) on a 9-point hedonic scale (1=Extremely dislike, 5=neutral, 9=Extremely like); and 3) evaluation of the "acceptability," "purchase intent," and "purchase intent after knowing that the salad contains amaranth microgreens" on a binomial scale (yes/no). All the panelists were instructed to rinse their mouths with water between each sample to minimize the effect of the order of presentation. Participation was voluntary and the consumers were informed about the ingredients, and the use of the hedonic scale with respect to the 7 attributes.

In total, there were 63 consumers. Their ages were within a range of $18-24$ years old in around 59\% and between 25-34 years old in 29\%. Among the consumers, $59 \%$ were women and $41 \%$ were men.

\section{Statistical Analysis}

Given the total quantity of formulations (7), a balanced incomplete block design was used ro reduce consumer fatigue. With this statistical design, each consumer evaluated only 2 formulations according to the plan 11.2a $(t=7, k=2, r=6, b=21, \lambda=1, E=0.58$; Cochran and
Cox, 1957). The design was repeated 3 times. For the analysis of liking data collected from the hedonic scale, a balanced incomplete block design was used ro reduce consumer fatigue with a significance level of 0.05. For means comparison among formulations, Tukey's test was applied. To identify similarities among formulations considering all the attributes simultaneously, Principal Components Analysis and Cluster Analysis were used. To identify the critical attributes for acceptability and purchase intent, a multiple logistic regression analysis was used (Prinyawiwatkul and Chompreeda, 2007), where the significance of each of the coefficients associated to each attribute was determined according to the following model:

$$
\begin{aligned}
\ln \left(\frac{P}{1-P}\right) & =\beta_{0}+\beta_{1} \text { Appearance }+\beta_{2} \text { Color } \\
& +\beta_{3} \text { Aroma }+\beta_{4} \text { Texture }+\beta_{5} \text { Flavor } \\
& +\beta_{6} \text { Aftertaste }+\beta_{7} \text { Overall Liking }
\end{aligned}
$$

To identify the effect of providing additional information to the consumer (the use of amaranth microgreens in the salad ingredients) on the purchase intent, the McNemar test was used. The R software version 4.0.2 was used with the integrated development environment of RStudio 1.3.959.

\section{RESULTS AND DISCUSSION}

In the variance analysis of the liking level for sensory attributes, no significant difference was found among the formulations for attributes of color, texture, flavor, aftertaste, and overall liking. In general, consumers indicated that they liked the salad samples in a range of 6 (like slightly) and 7 (like moderately). These results suggest that even with different proportions of ingredients in the formulations, consumers liked most of the attributes of the salads, and adding amaranth microgreens had no significant impact on consumer liking. A significant difference was found for the appearance and aroma attributes in a range of 5 (neutral) and 7 (like moderately). In the case of appearance, the lowest value was for formulation 4 (lettuce $22 \%$, amaranth $56 \%$, and carrot $22 \%$ ), which was one of the formulations with the highest proportion of amaranth. Paakki et al. (2019) studied the impact of color intensity and color contrasts in mixed salads. These authors found that salads with more contrast in their colors were more attractive to consumers since they were associated with freshness, variety, and complexity. In the case of aroma, the lowest values were for formulations 4 and 6 , both 
with the highest proportions of amaranth microgreens. This suggests that the aroma of amaranth microgreens could impact the level of liking, but not at a level that causes rejection. According to Kyriacou et al. (2016), microgreens usually have more intense flavors than sprouts. In general, the liking values for the attributes studied were similar to those found by Senevirathne et al. (2019) in salads prepared with different species of microgreens (Table 2).

The multivariate analysis of the results from the principal components and cluster analyses is shown in Figures 1 and 2. The formulations were projected in the first two principal components: AXIS1 (which explained $74.47 \%$ of the total variability) and AXIS2 (which explained $13.04 \%$ of the total variability), for a total of $87.51 \%$. The formulations were projected along this line, where the closest were the most visually similar between them according to the values (on the hedonic scale) that they were assigned in their attributes. Formulation 7, with the highest

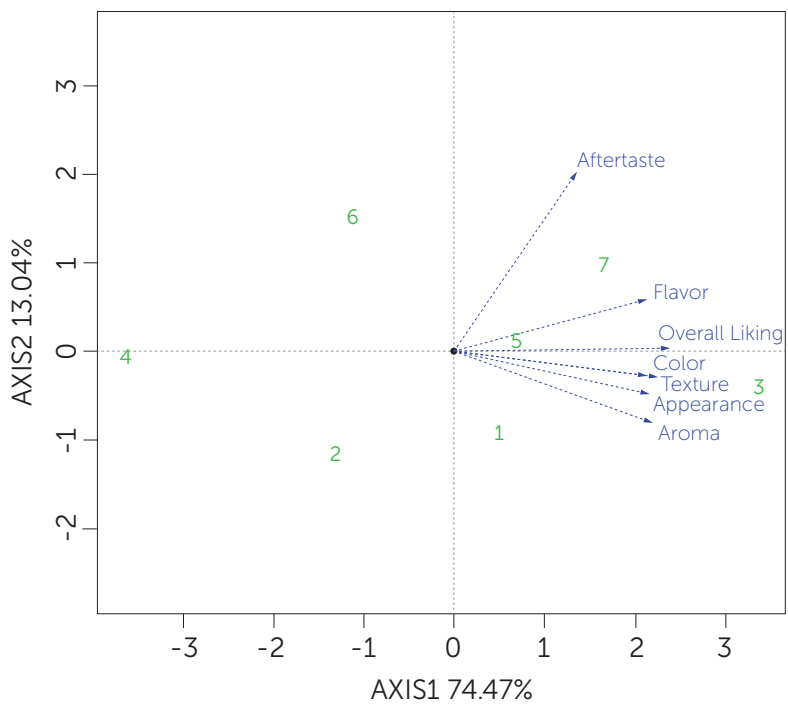

Figure 1. Biplot constructed with liking values plotting formulations and attributes in two dimensions. proportion of carrot, was pleasant to the consumer in its aftertaste, flavor, and overall liking attributes, as was Formulation 3 in its color, texture, appearance and smell attributes, with an even balance in its three ingredients. Formulations 1 and 5 were at an intermediate level, while formulations 2 (with a high proportion of lettuce), 4, and 6 (with high proportions of amaranth microgreens) were at the lowest level. Caracciolo et al. (2020) found that although visual appearance is important, acceptability is determined by flavor and texture. Cluster analysis allowed two groups to be visualized, clearly separating formulations 2, 4, and 6 from the rest.

The multiple logistic regression analysis is presented in Table 3. In this analysis, the coefficients for each attribute in the estimated model for acceptability were not significant. This indicates that no single attribute had a significant impact on the acceptability of the salads. Regarding purchase intent, only overall liking had a significant impact $(P=0.0005)$, indicating that consumers

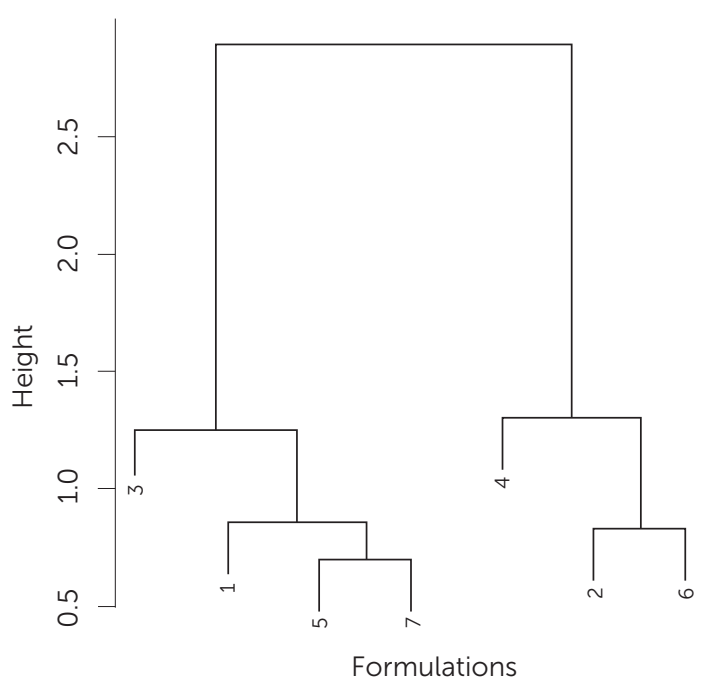

Figura 2. Dendrogram showing two groups of formulations with similar levels of liking.

\begin{tabular}{|c|c|c|c|c|c|c|c|}
\hline Formulation & Appearance & Color & Aroma & Texture & Flavor & Aftertaste & Overall Liking \\
\hline 1 & $6.50 \pm 0.99 a b$ & $6.89 \pm 1.13 a$ & $7.11 \pm 1.08 \mathrm{ab}$ & $7.11 \pm 1.37 a$ & $6.94 \pm 1.43 a$ & $6.22 \pm 1.40 a$ & $6.94 \pm 1.11 a$ \\
\hline 3 & $7.39 \pm 0.92 a$ & $7.44 \pm 1.15 a$ & $7.28 \pm 1.13 a$ & $7.33 \pm 1.08 a$ & $7.33 \pm 1.24 a$ & $6.44 \pm 1.46 a$ & $7.33 \pm 0.97 a$ \\
\hline 4 & $5.94 \pm 1.26 b$ & $6.28 \pm 1.60 a$ & $5.89 \pm 1.49 b$ & $6.28 \pm 1.49 a$ & $6.44 \pm 1.54 a$ & $6.17 \pm 1.20 a$ & $6.33 \pm 1.53 a$ \\
\hline 6 & $6.83 \pm 1.04 a b$ & $6.72 \pm 1.07 a$ & $6.00 \pm 0.97 b$ & $6.44 \pm 1.95 a$ & $6.78 \pm 1.56 a$ & $6.56 \pm 1.42 a$ & $6.78 \pm 1.31 a$ \\
\hline 7 & $6.83 \pm 1.10 a b$ & $7.22 \pm 1.35 a$ & $6.72 \pm 1.36 a b$ & $6.83 \pm 1.50 a$ & $7.33 \pm 1.41 \mathrm{a}$ & $6.56 \pm 1.42 a$ & $7.11 \pm 1.18 a$ \\
\hline
\end{tabular}

* Mean values \pm standard deviation. Means with the same letter in the same column are not significantly different according to Tukey's test at $\alpha=0.05$ 
relied on the combination of salad attributes to determine purchase intent. Formulation 4 was rated with the lowest acceptability and purchase intent (50\%) and Formulation 5 with the highest (100\%). Michell et al. (2020) found that familiarity with microgreens, cost, availability, and shelf life are also key factors in determining purchase intent of microgreens.

In general, the results of the analysis of variance, Principal Components Analysis, and Multiple Logistic Regression Analysis suggest that salad formulations that are balanced in their ingredient proportions and those with a slightly higher proportion of carrots were the best rated by consumers (Formulations 3 and 5).

The result of McNemar's test was not significant, indicating that informing consumers that the salad contains amaranth microgreens does not change their purchase intent, which was generally favorable for most formulations. Renna et al. (2017) emphasize that the culinary promotion of microgreens has great potential to integrate these ingredients into international gastronomy and foster the use of local edible species.

\section{CONCLUSIONS}

The aroma of amaranth can impact the level of liking of salads prepared with this crop's microgreens without reaching rejection. The use of carrots in combination with amaranth microgreens can improve the acceptability of salads. Salad formulations with amaranth proportions of 22 to $33.3 \%$ have more opportunity in purchase intent. In general, salads with amaranth microgreens were well received by consumers and represent an alternative for the diversification of the crop.

\section{ACKOWLEDGEMENTS}

The authors thank the Colegio de Postgraduados Córdoba Campus for the support granted to carry out the study.

\section{REFERENCES}

Caracciolo, F., El-Nakhel, C., Raimondo, M., Kyriacou, M.C., Cembalo,

L., De Pascale, S. \& Rouphael Y. (2020). Sensory Attributes and Consumer Acceptability of 12 Microgreens Species. Agronomy 10(7): 1043. doi: 10.3390/agronomy10071043

Choe, U., Lucy, L., Thomas, Y., \& Whang, T. (2018). The science behind Microgreens as an exciting new food for the XX century. Journal of Agricultural and Food Chemistry, 66(44):11519-11530. doi: 10.1021/acs.jafc. 8b03096

Cochran, W.G. \& Cox, G.M. 1957. Experimental designs. 2nd ed., New York: John Wiley \& Sons. $617 \mathrm{p}$

Kyriacou, M.C., Rouphael, Y., Di Gioia, F. Kyratzis, A., Serio, F., Renna,

\begin{tabular}{|c|c|c|c|c|}
\hline \multirow{2}{*}{ Attibutes } & \multicolumn{2}{|c|}{ Acceptability } & \multicolumn{2}{|c|}{ Purchase Intent } \\
\hline & Estimated & $\operatorname{Pr}(>|z|)$ & Estimated & $\operatorname{Pr}(>|z|)$ \\
\hline Appearance & 0.2678 & 0.7135 & 0.3688 & 0.2211 \\
\hline Color & 1.2512 & 0.1058 & -0.1120 & 0.2211 \\
\hline Aroma & -0.2982 & 0.6160 & 0.0195 & 0.9458 \\
\hline Texture & 0.0515 & 0.9165 & -0.0552 & 0.8458 \\
\hline Flavor & 0.8699 & 0.2461 & 0.5406 & 0.1282 \\
\hline AfterTaste & -0.0722 & 0.9096 & 0.0016 & 0.9956 \\
\hline Overall Liking & 0.6879 & 0.3679 & 1.3909 & 0.0005 \\
\hline
\end{tabular}

$\operatorname{Pr}(>|z|)$ values smaller than 0.05 indicate a significant impact of the attribute on salad acceptability or purchase intent.

M., De Pascale, S., Santamaria, P. (2016) Micro-scale vegetable production and the rise of microgreens. Trends in Food Science \& Technology. 57 (1): 103-115. http://dx.doi.org/10.1016/j. tifs.2016.09.005

Kou, L., Lou, Y., Yang, T., Xiao, Z., Turner, E. R., Lester, G. E., Camp, M. J. (2013). Postharvest biology, quality and shelf life of buckwheat microgreens. LWT - Food Science and Technology 51:73-78. doi:10.1016/j.lwt.2012.11.017

Michell, K.A., Isweiri, H., Newman, S.E., Bunning, M., Bellows, L.L., Dinges, M.M., Grabos, L.E., Rao, S., Foster, M.T., Heuberger, A.L., Prenni, J.E., Thompson, H.J., Uchanski, M.E., Weir, T.L., \& Johnson S.A. (2020). Microgreens: Consumer sensory perception and acceptance of an emerging functional food crop. Journal of Food Science. 85 (4): 926-935. doi: 10.1111/1750-3841.15075

Paakki, M., Sandel, M., Hopia, A. (2019) Visual attractiveness depends on colorfulness and color contrasts in mixed salads. Food Quality and Preference. 76(1): 81-90. https://doi.org/10.1016/j. foodqual.2019.04.004

Prinyawiwatkul, W., \& Chompreeda P. (2007). Applications of discriminant and logistic regression analysis for consumer acceptance and consumer-oriented product optimization study (chapter 16). In: Beckley JH, Foley M, Topp EJ, Huang JC, Prinyawiwatkul $W$, editors. Accelerating new food product design and development. Ames, lowa: Blackwell Publishing Professional

Rennaa, M., Di Gioiab, F., Leonia, B., Mininnib, C., \& Santamariaa, P. (2017). Culinary Assessment of Self-Produced Microgreens as Basic Ingredients in Sweet and Savory Dishes. Journal of Culinary Science \& Technology. 15(2):126-142. doi:10.1080/1 5428052.2016.1225534

Slavin, J.L. \& Lloyd, B. (2012). Health Benefits of Fruits and Vegetables. Advances in Nutrition 3(4):506-516, doi:10.3945/an.112.002154

Xiao, Z., Codling, E. E., Luo, Y., Nou, X., Lester, G. E., \& Wang, Q. (2016). Microgreens of Brassicaceae: Mineral composition and content of 30 varieties. Journal of Food Composition and Analysis 49 (1): 87-93. doi:10.1016/j.jfca.2016.04.006

Xiao, Z. L., Lester, G. E.; Park, E. H., Saftner, R. A., Luo, Y. G., \& Wang, Q. (2015). Evaluation and correlation of sensory attributes and chemical compositions of emerging fresh produce: Microgreens. Postharvest Biology and Technology. 110:140148. doi:10.1016/j.postharvbio.2015.07.021 